\title{
Effect of roll-compaction and milling conditions on granules and tablet properties
}

\author{
Lucia Perez-Gandarillas $^{\mathrm{a}, *}$, Ana Perez-Gago $^{\mathrm{b}}$, Alon Mazor ${ }^{\mathrm{a}}$, Peter Kleinebudde ${ }^{\mathrm{b}}$, Olivier Lecoq ${ }^{\mathrm{a}}$, \\ Abderrahim Michrafy ${ }^{a}$
}

${ }^{a}$ Université de Toulouse, Mines Albi, CNRS, Centre RAPSODEE, Albi, France

${ }^{\mathrm{b}}$ Institute of Pharmaceutics and Biopharmaceutics, Heinrich-Heine-University, Dusseldorf, Germany

\begin{abstract}
A B S T R A C T
Dry granulation is an agglomeration process used to produce size-enlarged particles (granules), improving the handling properties of powders such as flowability. In this process, powders are compacted using a roll press to produce ribbons, which are milled in granules used further in the tableting process. The granule and tablet properties are influenced by the existence of different designs of the roll compactors, milling systems and the interaction between process parameters and raw material properties. The main objective of this work was to investigate how different roll-compaction conditions and milling process parameters impact on ribbons, granules and tablet properties, highlighting the role of the sealing system (cheek plates and rimmed roll). In this context, two common excipients differing in their mechanical behaviour (MCC and mannitol) are used. The study is based on the analysis of granule size distribution together with the characterization of loss of compactability during die compaction.

Results show that the tensile strength of tablets is lower when using granules than when the raw materials are compressed. Moreover, the plastic material (MCC) is more sensitive than the brittle one (mannitol). Regarding the roll-force, it is observed that the higher the roll force, the lower the tensile strength of tablets from granulated material is. These findings are in agreement with the literature. The comparison of sealing systems shows that the rimmed-roll system leads to slightly stronger tablets than the use of cheek plates. In addition, the use of the rimmed-roll system reduces the amount of fines, in particular when high roll force is applied. Overall, it can be concluded that roll-compaction effect is predominant over the milling effect on the production of fines but less significant on the tablet properties. This study points out that the balance between a good flowability by reducing the amount of fines and appropriate tablet strength is achieved with rimmed-roll and the highest roll-force used.
\end{abstract}

\section{Keywords:}

Roll-compaction

Ribbon

Sealing system

Granule

Fines

Tablet

\section{Introduction}

Dry granulation by roll compaction is a size-enlargement technique widely used in the pharmaceutical industry. Generally, powders with poor flowability are compacted using a roll press to produce ribbons, which are milled in granules. The produced granules with improved flowability are used in further forming processes as tableting or capsule filling. The major advantage of dry granulation is the continuous production of granules without drying stage, leading to the reduction in costs [1]. This process is well suited for powders sensitive to water.

\footnotetext{
* Corresponding author.

E-mail address: lucia.gandarillas@mines-albi.fr (L. Perez-Gandarillas).
}

The existence of different roll-compactor designs and the diversity of operational parameters and material properties render the interpretation of the intrinsic properties of the granules and the resulting properties of tablets difficult. According to this, it is necessary to control the quality of the intermediate products (ribbons and granules) in order to optimize the properties of the final products (tablets). In general, a specific granule size must be achieved and the amount of fines, which is the most important parameter influencing flowability, should be limited especially when active ingredients are involved in the formulation. On the other hand, the enlargement process improves the flow but the tablet tensile strength is reduced due to limited binding potential which is partially consumed in the compression step [2]. The final goal is to keep the balance between loss of reworkability (reduction in tablet's strength), caused by dry agglomeration, and good flow, 
achieved through the increase in particle size. Therefore, quality of intermediate products should be maintained across the different unit operations of the process.

The effect of the roll-compaction step on the properties of ribbons and tablets has been widely reported in the literature [3-5]. Inghelbrecht and Remon [3] studied the compaction of lactose by analysing different process parameters, such as compaction pressure, roll speed, vertical and horizontal screw speed and concluded that roll-compaction pressure was the most important parameter to be controlled. During the roll-compaction step, it is also extremely important to control the non-compacted powder, which can be considered as fines if the dry granulation process takes place in a continuous mode. In this context, Wagner et al. [6,7] studied the dry granulation of different grades of mannitol and showed clearly the decrease in the amount of fines by increasing the roll pressure. In their work, the authors also analysed the compactability of the powders after roll-compaction. They concluded that the higher is the roll-compaction force, the lower is the tablet tensile strength. This effect, known as loss of reworkability, has been previously reported in the literature [8-14]. However, in contrast to this, Kuntz et al. [15] showed an increase in compactability for acetames after dry granulation.

Another parameter influencing roller compaction operation, which has received less attention, is the side sealing system that avoids the leakage of powder during the process. Roll presses are generally sealed in order to prevent the escape of powder during the compaction [16]. Two types of sealing systems are available for the commercial roll-compactors: cheek plates and rimmedroll. The type of sealing system not only affects the amount of non-compacted powder, but also confers certain properties to the ribbons such as density distribution across the ribbon width [17-19].

After being compacted, the ribbons are subsequently milled into granules. Regarding the milling step, many variables, such as mill type, mill design, screen size, speed and mode of oscillation, have a significant influence on the quality of granules. The most important resultant property of the milling step is the particle size distribution. In order to improve the efficiency of dry granulation by roll compaction, it is required to control the granule size through the selection of appropriate milling conditions and to relate the size distribution to the properties achieved as a result of the previous roll compaction step. Some authors have reported research work on the effect of the milling on granules properties. Samanta et al. [20] evaluated the effect of conical mill process parameters and concluded that the type of impeller and the screen are the settings with the highest influence on the granule size distribution. On the other hand, Vendola and Hancock [21] compared four types of milling systems for two dry-granulated placebo formulations; the evaluation was done based on the compactability, resulting that the mill type and the granulation size distribution did not greatly influence the compactability of tablets.

The above studies highlight the complexity of the powder behaviours and the process parameter interactions in dry granulation operations. The main objective of this work was the investigation of how different roll-compaction conditions and milling parameters affect the properties of the intermediate and final products (ribbons and granules) in order to get a deeper understanding of the relationship between powder properties and process parameters during rolling, milling and die compaction. The process should be seen as a whole and the study of the downstream processes (milling and tableting) is necessary for the understanding of roll compaction. The analysis of granule size distribution together with the characterization of the compactability of granules can help in the determination of the optimal conditions for these systems and design of granules with a good quality for tableting.

\section{Materials and methods}

\subsection{Materials}

Two common pharmaceutical excipients were used: microcrystalline cellulose (MCC, Avicel ${ }^{\circledR}$ PH-101, FMC Biopolymer, USA), considered generally as plastic material and spray-dried mannitol (Pearlitol $^{\circledR}$ 200SD, Roquette, France), which has higher compactability compared with the unprocessed mannitol [6]. It is the plastic or brittle character of each material that interests us in this study. These materials, known as examples of materials with different mechanical behaviours, have been investigated in previous research works. In particular, how the roll-compaction of MCC and mannitol affects the ribbon and granule properties $[2,6,7,10,11]$. Moreover, in their recent work, Pérez Gago and Kleinebudde [22] studied the roll-compacted mixtures of the above excipients to better understand the impact of the dosage on the ribbon microhardness and granule size distribution. The differences of mechanical behaviour under compaction were determinants in their selection in this study.

\subsection{Powder characteristics}

The basic characteristics of the excipients used in this study are presented in Table 1 and scanning electron microscopy images (Philips XL30, Netherlands) of these excipients are shown in Fig. 1. The bulk densities were obtained from the manufacturer and the true densities were determined by using a helium pycnometer (AccuPyc 1330, Micromeritics Instrument Corp., USA).

\subsection{Roll compaction}

The preparation of ribbons was performed using a Gerteis roll compactor: Mini-Pactor ${ }^{\circledR}$ 250/25 (Gerteis Machinen + Processengineering AG, Switzerland). The configuration of this compactor consists in an inclined setup of the rolls. The Mini-Pactor ${ }^{\circledR}$ can be equipped with two side-sealing systems: cheek plates and rimmed-roll (Fig. 2). The cheek plates are two side seals, which are fixed beside the rolls. On the other hand, rimmed-roll system consists of two flat rings attached to one of the rolls and that rotate together with the roll.

Different batches of ribbons were produced under different conditions. The roll-compactor is placed in a climate room $\left(21^{\circ} \mathrm{C}\right.$ and $45 \% \mathrm{RH}$ ) where also the powders were stored prior to compaction. The two types of sealing systems, presented above, and two specific compaction forces ( 4 and $8 \mathrm{kN} / \mathrm{cm}$ ) were used. Therefore, 4 batches of ribbons were produced for each excipient.

For the experiments, knurled rolls were used, the roll speed was $2 \mathrm{rpm}$ and the gap was controlled by the automatic feedback system and kept constant at $1.5 \mathrm{~mm}$. The ribbons were collected once the steady state was achieved for each set of conditions.

\subsection{Milling}

For continuous production, the Mini-Pactor ${ }^{\circledR}$ has integrated granulators, which consist of a moving rotor and a fixed sieve of

\section{Table 1}

Basic characteristics of excipients.

\begin{tabular}{llll}
\hline Material & $\begin{array}{l}\text { Mean particle size } \\
(\mu \mathrm{m})\end{array}$ & $\begin{array}{l}\text { Bulk density } \\
\left(\mathrm{g} / \mathrm{cm}^{3}\right)\end{array}$ & $\begin{array}{l}\text { True density } \\
\left(\mathrm{g} / \mathrm{cm}^{3}\right)[\mathrm{n}=3]\end{array}$ \\
\hline MCC & 50 & 0.32 & 1.56 \\
Mannitol & 170 & 0.48 & 1.47 \\
\hline
\end{tabular}


(a)

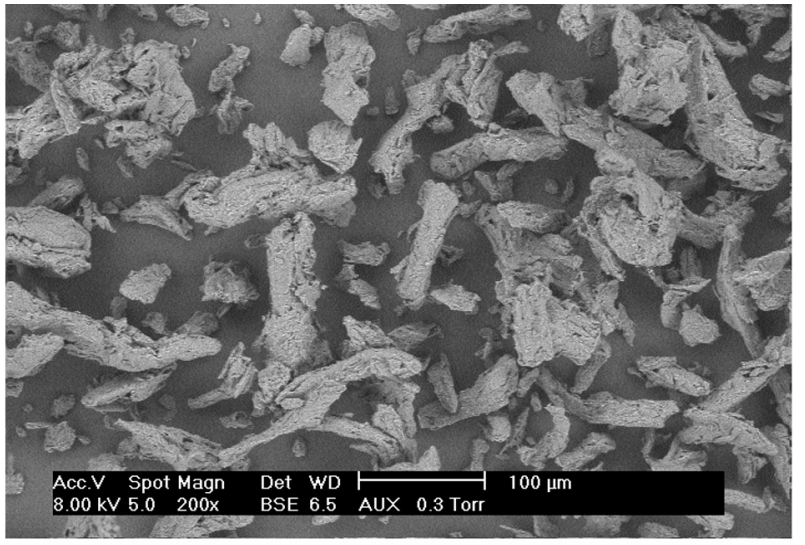

(b)

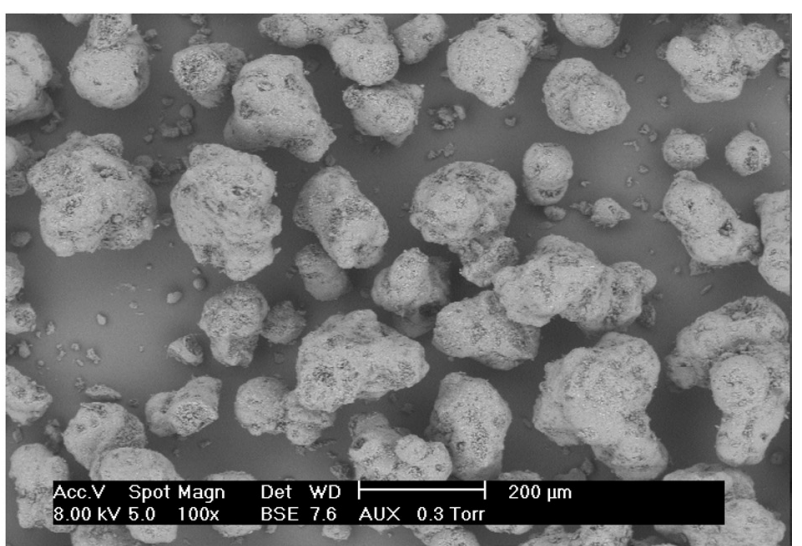

Fig. 1. Scanning electron microscopy images of powders (a) MCC 101 and (b) mannitol 200SD.

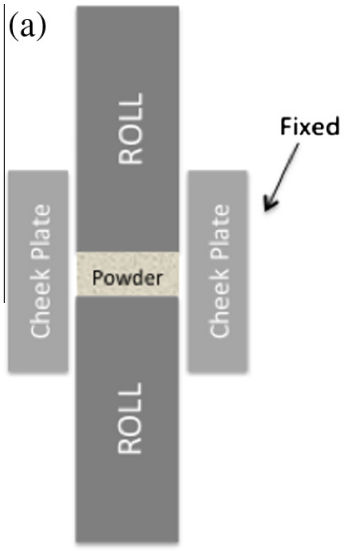

(b)

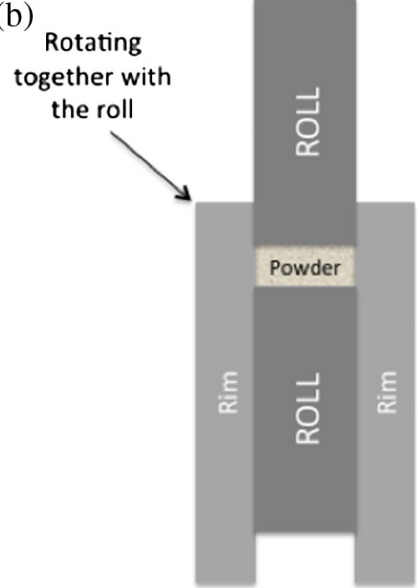

Fig. 2. Front view of sealing system designs of Mini-Pactor ${ }^{\circledR}$ (a) cheek plates and (b) rimmed-roll.

a chosen size. Milling parameters such as rotor speed and angle of rotation can be adjusted.

Two types of rotors are available for the Mini-Pactor ${ }^{\circledR}$ : open star rotor and pocket mould-grooved (Fig. 3). The rotor speed can vary between 0 and $160 \mathrm{rpm}$ and the rotation angle can be adjusted from 0 to $720^{\circ}$ in clockwise direction, counter-clockwise or a combination of both.

In this study, different settings were compared for both types of rotors. The ribbons were milled using a fixed sieve of $1 \mathrm{~mm}$ at 30 and $120 \mathrm{rpm}$ of speed and the rotating angles were $360^{\circ}$ clockwise (rotation) and $150^{\circ} / 150^{\circ}$ clockwise/counter-clockwise

(a)

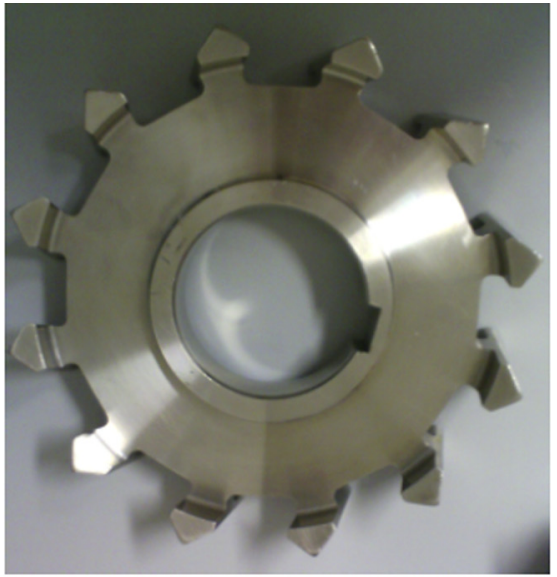

(b)

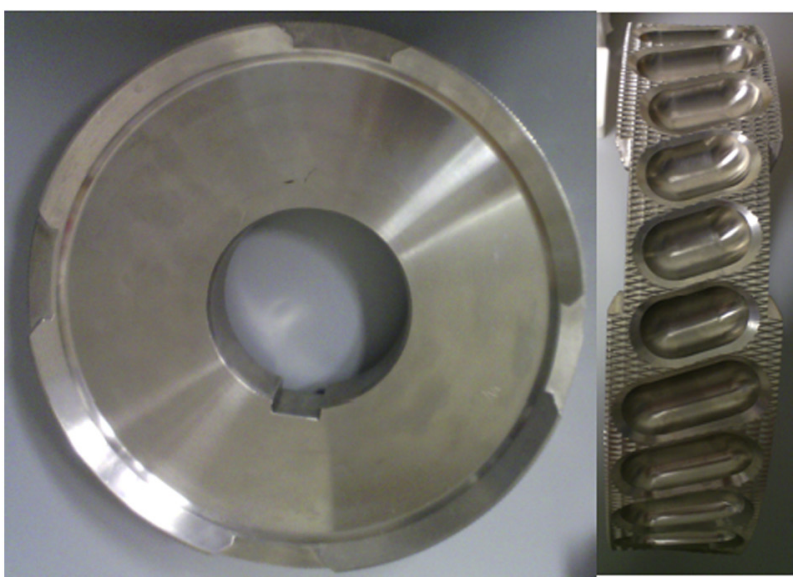

Fig. 3. Rotor types (a) open star and (b) pocket mould-grooved.

(oscillation). In order to avoid the presence of non-compacted powder in the milling chamber, the ribbons were collected after compaction and introduced into the milling chamber, separately from the non-compacted powder (previously brushed off). The granules were imaged with a scanning electron microscope (Philips XL30, Netherlands).

\subsection{Ribbon density}

The ribbon relative density (Eq. (1)) is calculated from the powder true density (Table 1 ) and the ribbon envelope density, which was measured using a GeoPyc ${ }^{\circledR} 1360$ Envelope Density Analyzer (Micromeritics Instrument Corp., USA).

The GeoPyc ${ }^{\circledR}$ measures the envelope density of irregular shape samples based on a displacement measurement technique. The ribbon envelope density ( $\rho_{\text {envelope }}$ ) is calculated following (Eq. (2)), where $m$ is the mass of the ribbon $(\mathrm{g}), d_{2}$ and $d_{1}$ are the displacements of the punch $(\mathrm{mm})$ with and without the ribbon sample in the chamber, respectively, and $f$ is the conversion factor $\left(\mathrm{cm}^{3} /\right.$ $\mathrm{mm}$ ), which depends on the internal diameter of the chamber. Approximately, $5 \mathrm{~g}$ of sample was used in each measurement. The chamber used for the analysis had a diameter of $25.4 \mathrm{~mm}$, the consolidation force was $51 \mathrm{~N}$ and the conversion factor was $0.5153 \mathrm{~cm}^{3} / \mathrm{mm}$. The measurements were replicated three times and the mean value was considered.

$$
\begin{aligned}
& \rho_{\text {relative_ribbon }}=\frac{\rho_{\text {envelope }}}{\rho_{\text {true }}} \\
& \rho_{\text {envelope }}=\frac{\mathrm{m}}{\mathrm{V}_{\text {sample }}}=\frac{\mathrm{m}}{\left(\mathrm{d}_{2}-\mathrm{d}_{1}\right) \cdot \mathrm{f}}
\end{aligned}
$$




\subsection{Granules characterization}

The size distributions of the produced granules were determined by dynamic image analysis (Camsizer ${ }^{\circledR}$ XT, Retsch Technology GmbH, Germany). Representative samples of the granules (approximately $10 \mathrm{~g}$ ) were analysed using the X-Jet module and a pressure of $30 \mathrm{kPa}$. For reproducibility, the measurement was done three times for each batch of granules.

Controlling the granule size distribution and avoiding big amounts of fines are important to minimize the powder segregation during compression. Accordingly, for each batch, the amount of fines was estimated by $d_{10}$ (diameter at which $10 \%$ of the sample's volume lies below).

\subsection{Compaction of tablets}

An Instron ${ }^{\circledR}$ universal testing machine with a $30 \mathrm{kN}$ load cell was used to compress cylindrical flat tablets. For the comparison of tablet properties, either the mass or the volume of the materials should be kept constant. In this work, the mass was maintained constant. The tablets were prepared by pouring manually a mass of $0.300 \pm 0.005 \mathrm{~g}$ of material into a die of $11.28 \mathrm{~mm}$ of diameter (volume $1 \mathrm{~cm}^{3}$ ) and compacting them at different pressures (from $20 \mathrm{MPa}$ to $150 \mathrm{MPa}$ ). The compaction was made at room temperature $\left(25^{\circ} \mathrm{C}, 45 \pm 2 \% \mathrm{RH}\right)$ at $5 \mathrm{~mm} / \mathrm{min}$ of speed (quasi-static). For each pressure level, the mean of three replicates was calculated.

Different milling parameters result in different particle size distributions and wide ranges of granule size can exhibit different compaction properties. Therefore, to be able to compare the effect of roll-compaction and milling conditions on the mechanical properties of granules, granules were divided using sieve. This division allows evaluating and comparing the behaviour of granules under die compaction. The granule size range used for the die compaction study was $200-500 \mu \mathrm{m}$.

The relative density ( $\left.\rho_{\text {relative_tablet }}\right)$ of each tablet was calculated following (Eq. (3)), where $m$ is the tablet mass, $h$ and $D$ are the thickness and the diameter of the tablet respectively, measured after the ejection with a digital calliper, and $\rho_{t}$ is the true density measured with a helium pycnometer.

$\rho_{\text {relative_tablet }}=\frac{4 \mathrm{~m}}{\pi \mathrm{hD} \mathrm{D}^{2} \rho_{\mathrm{t}}}$

A diametric strength tester (Erweka TBH30, Erweka ${ }^{\circledR}$ Gmbh, Germany) was used to measure the diametrical crushing load of tablets $(\mathrm{n}=3)$. The tensile strength of the compacts $\left(\sigma_{t}\right)$ was calculated according to Fell and Newton [23]:

$\sigma_{t}=\frac{2 \cdot F}{\pi \cdot D \cdot H}$

where $F$ is the load required to break the tablet diametrically, and $D$ and $H$ are the diameter and the final height of the tablet, respectively.

\subsection{Statistical analysis}

A statistical analysis has been performed using MODDE Pro 11.0.1 (Umetrics, Malmö, Sweden) based on multiple linear regression (MLR). The design of experiments consists of five factors in two levels and two responses (Table 2). The type of material used was included as a qualitative factor. The relative significance of the different factors on the responses was evaluated through the coefficient plots, which display the regression coefficients with confidence intervals. The size of the model terms reflects the magnitude of the change in the response when a factor varies. If a response increases when a factor increases, the factor sign will
Table 2

Description of the design of experiments with different factors and responses.

\begin{tabular}{lll}
\hline Factors & Levels & \\
\hline Sealing system & Cheek plates & Rimmed-roll \\
Roll-compaction force $(\mathrm{kN} / \mathrm{cm})$ & 4 & 8 \\
Mill type & Star granulator & Pocket mould-grooved \\
Milling speed $(\mathrm{rpm})$ & 30 & 120 \\
Angle $\left(^{\circ}\right)$ & 150 & 360 \\
Responses & & \\
$\mathrm{d}_{10}(\mu \mathrm{m})$ & & \\
Tensile strength $(\mathrm{MPa})$ & & \\
\hline
\end{tabular}

be positive. Therefore, the sign represents the relation of the influence (direct or inverse relation). A coefficient should be considered significant if the confidence interval does not cross the $\mathrm{X}$-axis.

\section{Results and discussion}

\subsection{Ribbon quality}

The quality of produced ribbons of MCC and mannitol showed dependency on the sealing system conditions and material properties.

The MCC ribbons (Fig. 4) produced using cheek plates as sealing system showed regular shape and length as well as approximately the same width as the roll. However, when using rimmed-roll, the ejected ribbons are confined between the rims and the roll during ejection. For this reason, a scraper is included in the roll press design, allowing the separation of the ribbons from the roll and resulting in the reduction in ribbon's length. In both cases (cheek plates and rimmed-roll), at higher force $(8 \mathrm{kN} / \mathrm{cm})$, the ribbons tended to laminate (separation of the ribbon into two or more layers after the ejection step due to the friction between the material and the rolls, which causes, in some cases, the stickiness of the ribbon to the rolls). Moreover, when high force and rimmed-roll were combined, not only lamination but also breakage (fracture of the ribbons into smaller pieces) in the middle of the width took place.

\section{(a)}

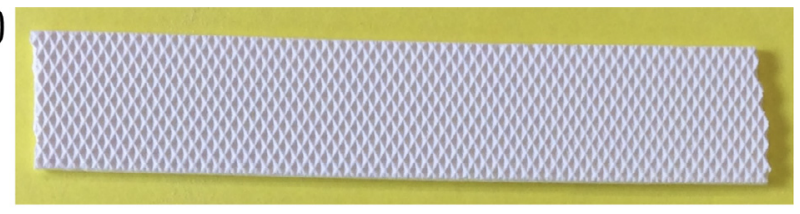

(b)

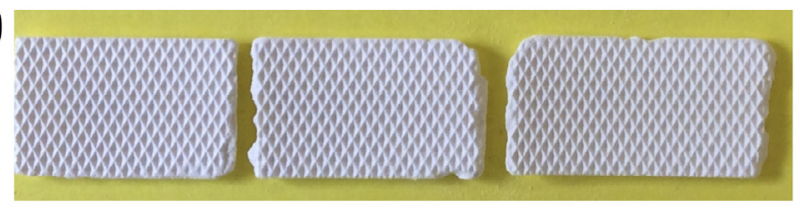

(c)

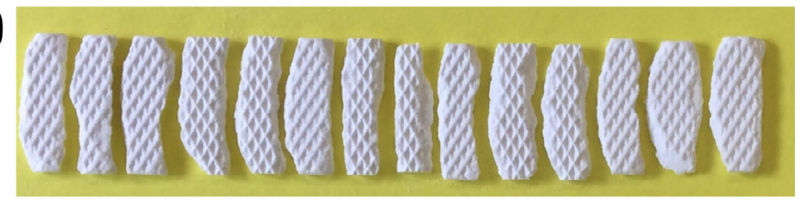

(d)

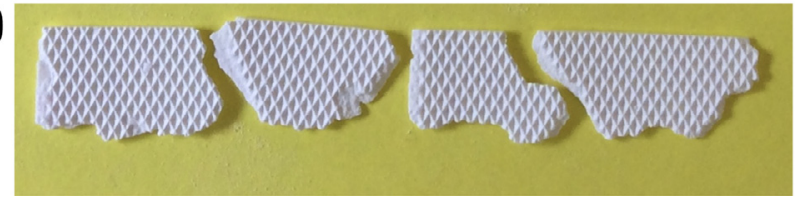

Fig. 4. MCC ribbons (a) CP, $4 \mathrm{kN} / \mathrm{cm}$; (b) CP, $8 \mathrm{kN} / \mathrm{cm}$; (c) RR, $4 \mathrm{kN} / \mathrm{cm}$; (d) RR, $8 \mathrm{kN} /$ $\mathrm{cm}[\mathrm{CP}=$ Cheek Plates, RR = Rimmed-roll; Roll compaction forces: 4 and $8 \mathrm{kN} / \mathrm{cm}]$. 
For the mannitol, the lamination tendency occurred under all the tested conditions due to its brittle behaviour (Fig. 5), meaning that it is only possible to obtain small fragments with irregular shapes. Furthermore, the ribbon fragments became smaller when using rimmed-roll as sealing system.

\subsection{Ribbon density}

Ribbon relative density is often considered as a good indicator of the ribbon quality. Fig. 6 shows the obtained values of relative density for each type of ribbon produced. The measured solid fraction showed different wide ranges for MCC (from 0.57 to 0.70 ) and mannitol (from 0.71 to 0.79 ). Comparing the materials under the same roll-compaction conditions, it can be observed that ribbons produced with mannitol are denser than the ones of MCC. This is probably due to the higher flowability of mannitol, which leads to more powder mass fed between the rolls.

It can be also observed that the higher densities are obtained at higher roll-force. Comparing the two sealing systems, similar values of density were obtained, slightly lower for rimmed-roll system.

\subsection{Granules morphology}

In general, shape and surface roughness have an impact during the filling and the rearrangement of particles in die compaction.

(a)

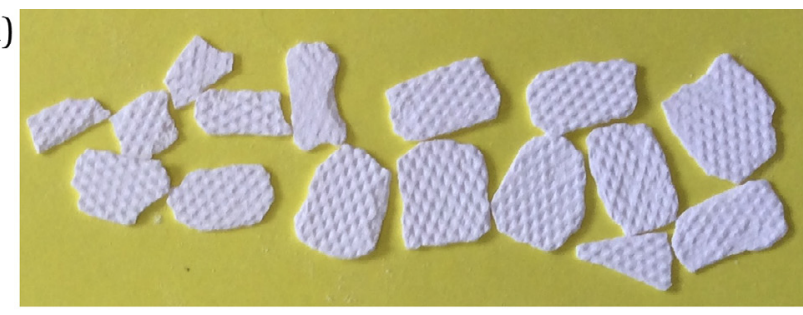

(b)

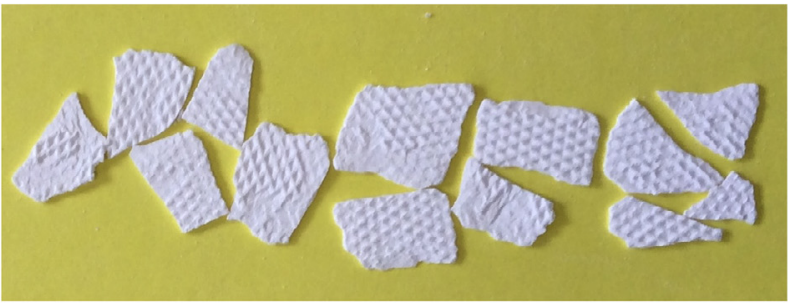

(c)

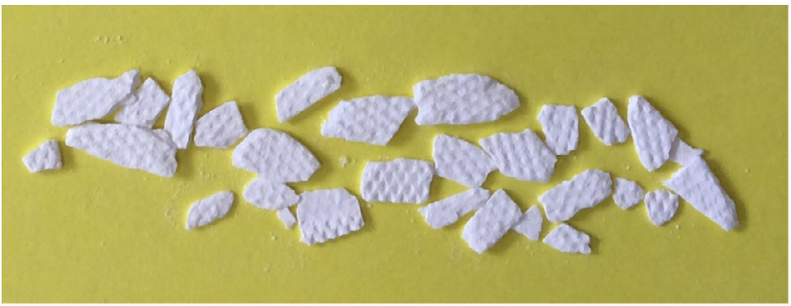

(d)

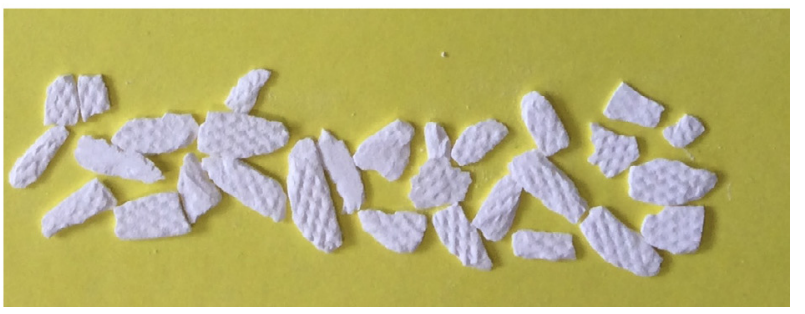

Fig. 5. Mannitol ribbons (a) CP, $4 \mathrm{kN} / \mathrm{cm}$; (b) CP, $8 \mathrm{kN} / \mathrm{cm}$; (c) RR, $4 \mathrm{kN} / \mathrm{cm}$; (d) RR $8 \mathrm{kN} / \mathrm{cm}[\mathrm{CP}=$ Cheek Plates, $\mathrm{RR}=$ Rimmed-roll; Roll compaction forces: 4 and $8 \mathrm{kN} /$ $\mathrm{cm}]$.
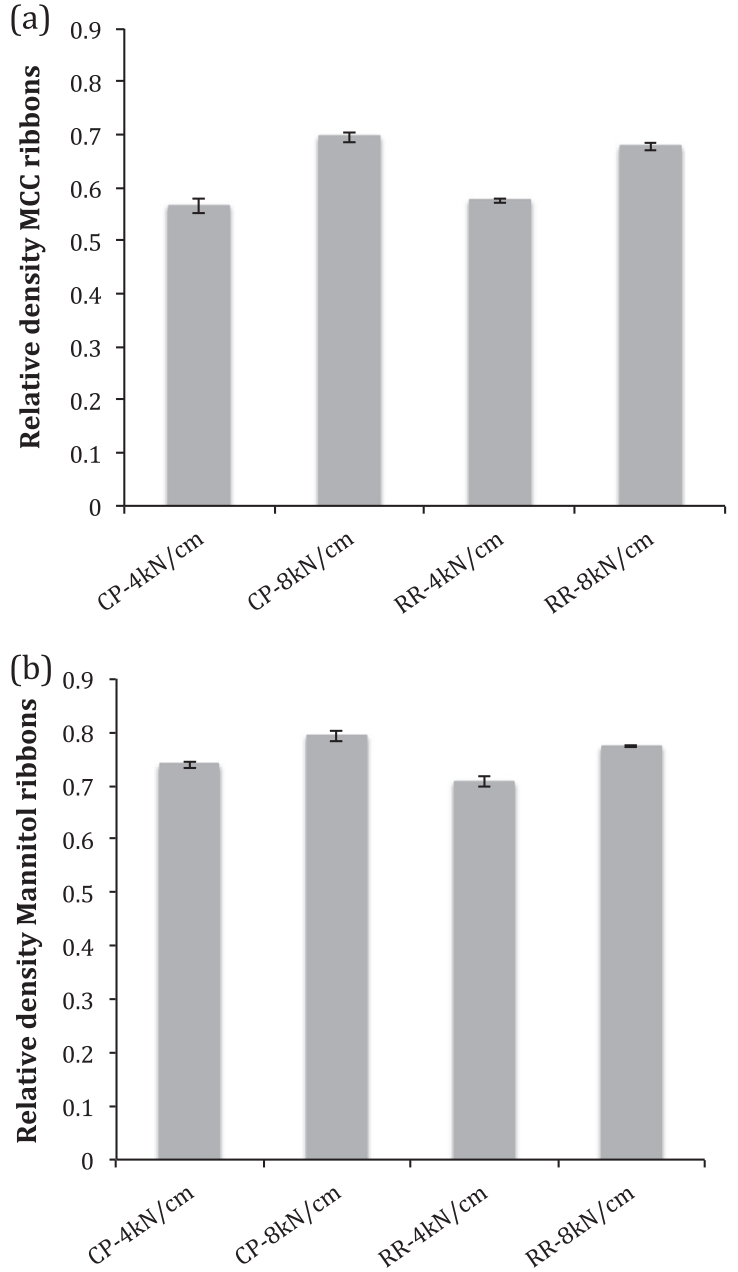

Fig. 6. Average relative density of ribbons (a) MCC, (b) mannitol ( $\mathrm{CP}=$ Cheek Plates, $\mathrm{RR}=$ Rimmed-roll; Roll compaction forces: 4 and $8 \mathrm{kN} / \mathrm{cm}$ ).

The observation of these characteristics can help in the understanding of the powder behaviour during die compaction. In this study, granules produced after milling the ribbons were imaged with a scanning microscope and they are shown in Figs. 7 and 8.

For granules from MCC, it can be observed that they represent an agglomeration of fibre-like single particles. At higher force, the density of granules is increased. It can be also observed that the higher is the roll-compaction force, the smoother the surface becomes. In general, rough surfaces and irregular shapes of granules improve the compactability due to a better mechanical inter-locking and inter-granular bonding [24,25], especially for plastically deforming materials [26].

For mannitol, the granules produced under different rollcompaction conditions (Fig. 8) do not show noticeable differences. Nevertheless, the granules are completely different from the original feed powder, which had a spherical shape (Fig. 1(b)).

\subsection{Granules size distribution}

In die compaction, the particle size distribution is of high interest in the resulting tablet's properties, in particular in die filling where demixing or segregation is one source of nonhomogeneity of tablet properties. For both materials, bimodal distributions were obtained, where the first term represents the fines and the other the coarser particles. The same bimodal profiles, which are characteristic for roll-compacted granules, were 


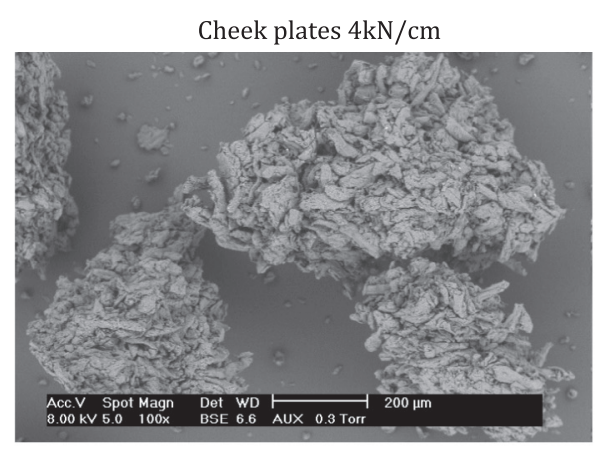

Rim rolls $4 \mathrm{kN} / \mathrm{cm}$

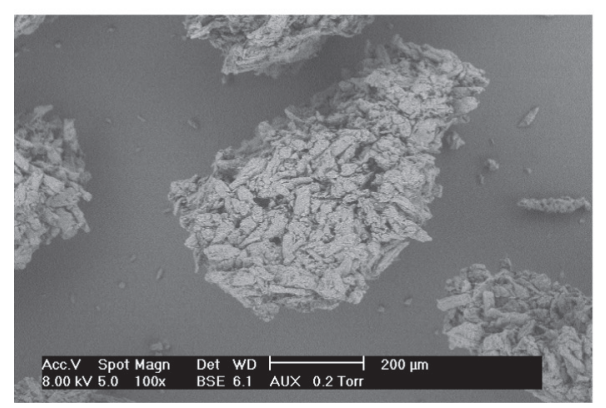

Cheek plates $8 \mathrm{kN} / \mathrm{cm}$

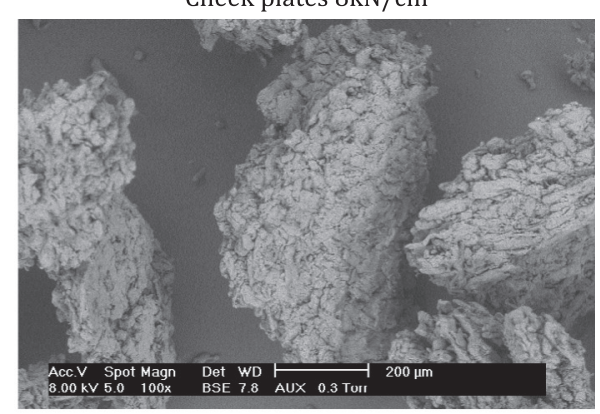

Rim rolls $8 \mathrm{kN} / \mathrm{cm}$

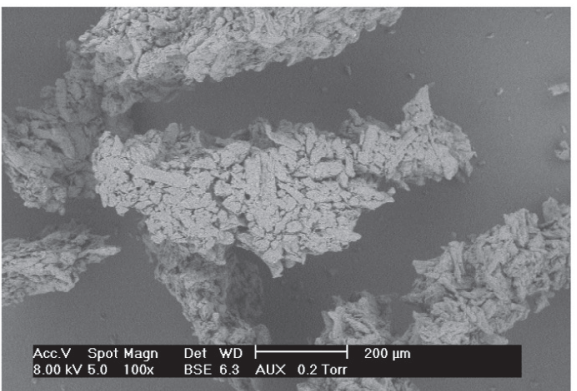

Fig. 7. Granules produced from MCC under different roll compaction conditions.

Cheek plates $4 \mathrm{kN} / \mathrm{cm}$

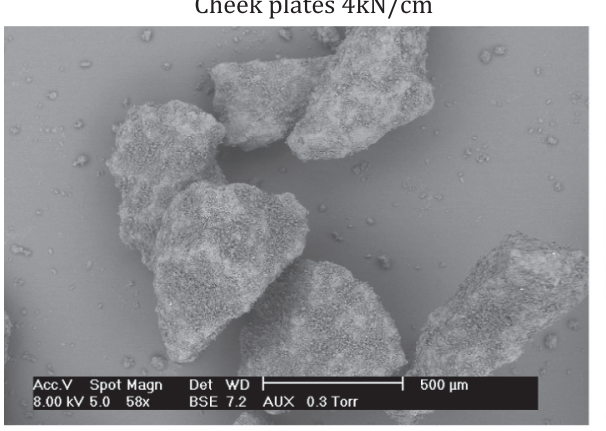

Rim rolls $4 \mathrm{kN} / \mathrm{cm}$

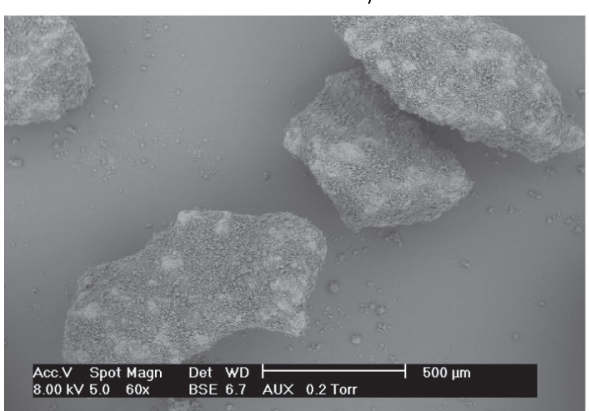

Cheek plates $8 \mathrm{kN} / \mathrm{cm}$

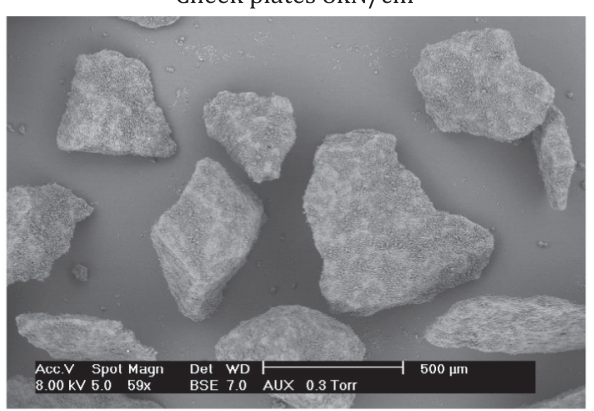

Rim rolls $8 \mathrm{kN} / \mathrm{cm}$

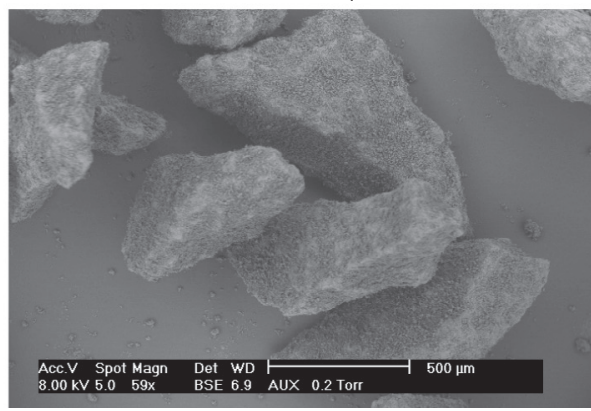

Fig. 8. Granules produced from mannitol under different roll compaction conditions.

obtained by Pérez Gago and Kleinebudde [22] for these two excipients. In this study, the analysis has been done based on the amount of fines produced. Reducing the amount of fines improves the flow properties of the final granulation and the weight variation during tableting [21].

As introduced in Section 2.6, the amount of fines was evidenced by $d_{10}$ (diameter at which $10 \%$ of the sample's volume lies below). Figs. 9 and 10 show the effect of different roll-compaction/milling conditions ( $\mathrm{X}$ axis) on the value of $\mathrm{d}_{10}$. Based on the definition of $d_{10}$, higher values of $d_{10}$ mean bigger size and, hence, less fines are produced under a specific set of parameters. Therefore, the smallest $\mathrm{d}_{10}$ value indicates the biggest amount of fines. In these figures, it was also pointed out the mean particle size of the original feed powder ( $50 \mu \mathrm{m}$ for MCC and $170 \mu \mathrm{m}$ for mannitol). Thus, if the $d_{10}$ value is below the horizontal line, it means that $10 \%$ of the volume of the sample has a size below the particle size of original feed powder, due to the compression action or to the breakage of single particles.

Results showed that, for MCC (Fig. 9), the produced granules from ribbons compacted with higher roll compaction force 


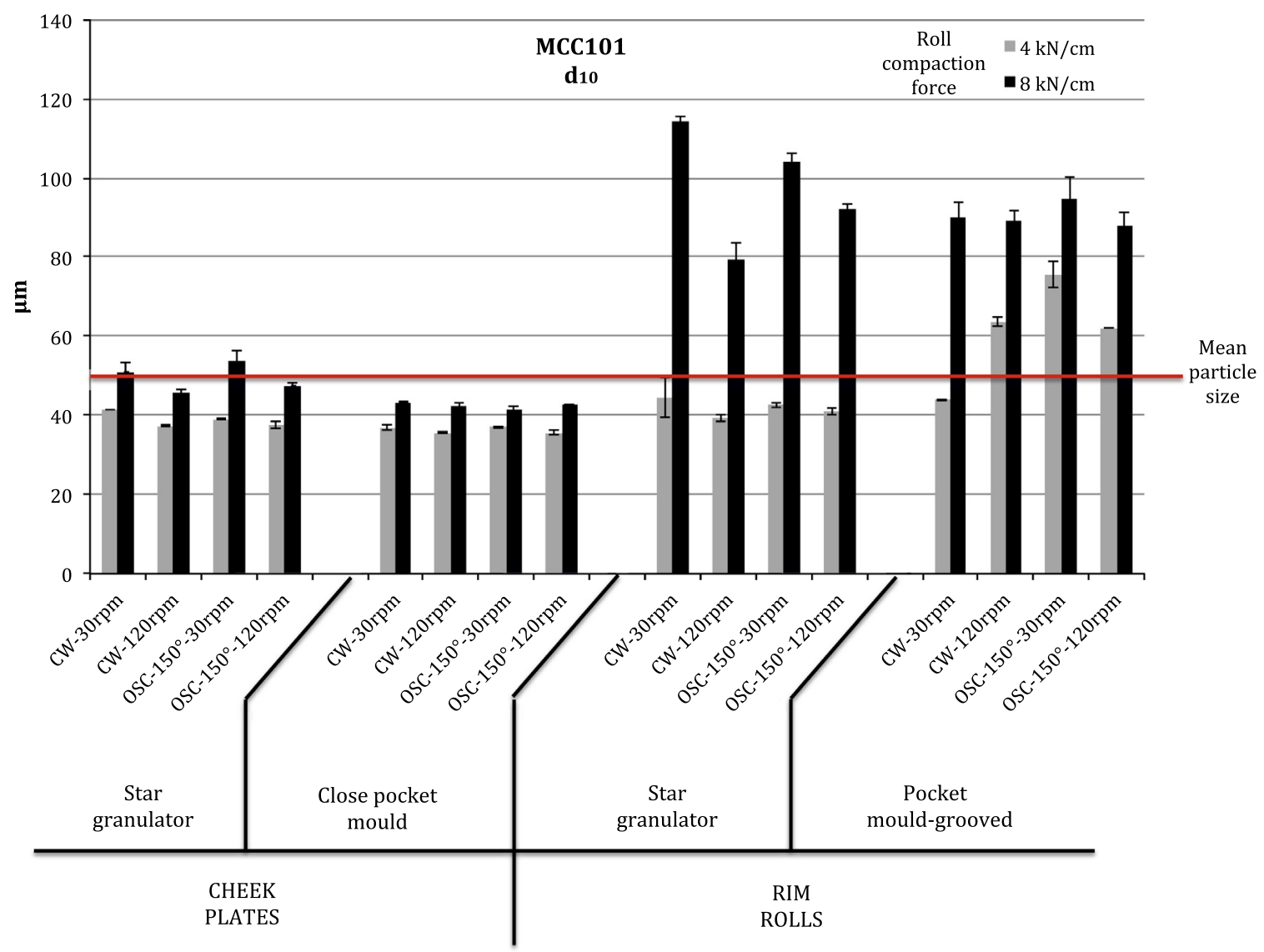

Fig. 9. $d_{10}$ of MCC granules batches $(C W=$ Clockwise; OSC = Oscillating). Mean particle size of MCC powder is $50 \mu \mathrm{m}$.

$(8 \mathrm{kN} / \mathrm{cm})$ generate less percentage of fines and coarser granules, having a longer residence time in the milling chamber. Conversely, low densified ribbons lead to a big amount of fine particles. These results are in agreement with others studies in the literature $[11,27]$, where the granule size increases with the compaction force. In general, for plastic material such as MCC, high-densified ribbons produce bigger granules and less fines, while weaker ribbons generate a big amount of fine particles. In addition, at high compaction-force, the use of rimmed-roll showed a reduction in the amount of fines compared to the cheek plates. The use of cheek-plates in the production of MCC ribbons induced an increase in the amount of fines, being the value of $\mathrm{d}_{10}$ below the particle size of as-received MCC powder. For mannitol (Fig. 10), also higher roll-compaction force $(8 \mathrm{kN} / \mathrm{cm})$ creates less amount of fines. This fact is even more evident when using the rimmed-roll system. Therefore, adopting the minimal fines approach, it can be concluded that to produce less fines, it is not only recommended to work at high roll-compaction force as proposed in the literature [6,7], but also to use rimmed-roll as sealing system.

Evaluating the effect of rotor type, it was observed during production that the milling step was faster for the star granulator. The star granulator is a good option for its high throughput capacity, being the residence time within the milling chamber shorter than for the pocket mould-grooved. On the other hand, the pocket mould granulator offers a different mechanism of milling, including pre-breaking as a primary step before the shearing action. Also, oscillating mode (clockwise/counter-clockwise) produces higher throughput than rotation (clockwise). Regarding the milling speed, it was reported in the literature [20] that, in general, when the milling speed is increased, the percentage of fines is increased as well. Nevertheless, the determination of the optimal milling parameters for both excipients is difficult, because there is not a clear tendency in the results and the performance depends not only on the milling conditions but also on the roll-compaction conditions.

For MCC ribbons compacted using cheek plates (Fig. 9), the values of $d_{10}$ are below the original particle size, indifferent to the rotor type, the speed or the angle of rotation. However, at $4 \mathrm{kN} / \mathrm{cm}$, the pocket-moulded granulator produced less fines (higher $\mathrm{d}_{10}$ ) than star granulator when rimmed-roll is used as sealing system. At $8 \mathrm{kN} / \mathrm{cm}$, rimmed-roll is also preferred but the difference in the amount of granules produced if the two milling systems are compared is less pronounced, although fewer fines are produced with star granulator. In summary, for MCC, the pocket mould-grooved is preferred to mill low-densified ribbons and star granulator for high-densified ribbons. For MCC, the minimum percentage of fines is produced when ribbons are produced at $8 \mathrm{kN} / \mathrm{cm}$ using rimmed-roll and milled at $30 \mathrm{rpm}$ clockwise using star granulator as milling system. On the contrary, for mannitol, the higher value of $d_{10}$ is obtained for ribbons produced at $8 \mathrm{kN} / \mathrm{cm}$ with rimmed-roll milled at $30 \mathrm{rpm}$ clockwise with the pocket mould-grooved granulator.

In order to support these statements, the evaluation of the effect of the operation conditions on the value of $\mathrm{d}_{10}$ was evaluated through the coefficient plot, presented in Fig. 11. It can be seen that the type of material is the first and most important factor to take into account as well as that more fines are produced with MCC than with mannitol. The specific roll-compaction force and the rimmedroll as sealing system have a proportional influence on $\mathrm{d}_{10}$, i.e. the higher the compaction force, the higher the $d_{10}$. As it was mentioned before, it is preferable to work at high roll-compaction force 


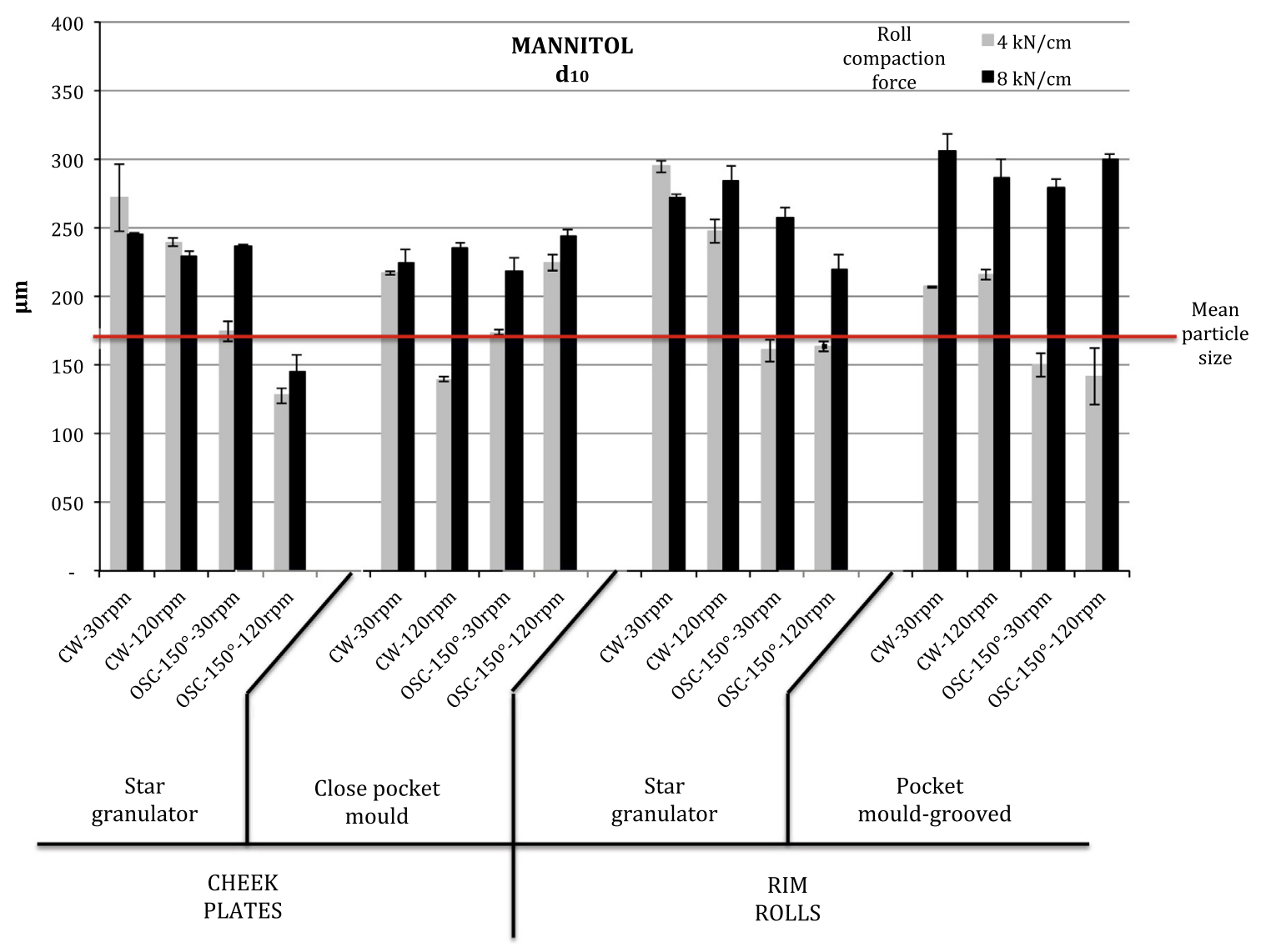

Fig. 10. $d_{10}$ of mannitol granules batches $(C W=$ Clockwise; OSC = Oscillating $)$. Mean particle size of mannitol powder is $170 \mu \mathrm{m}$.

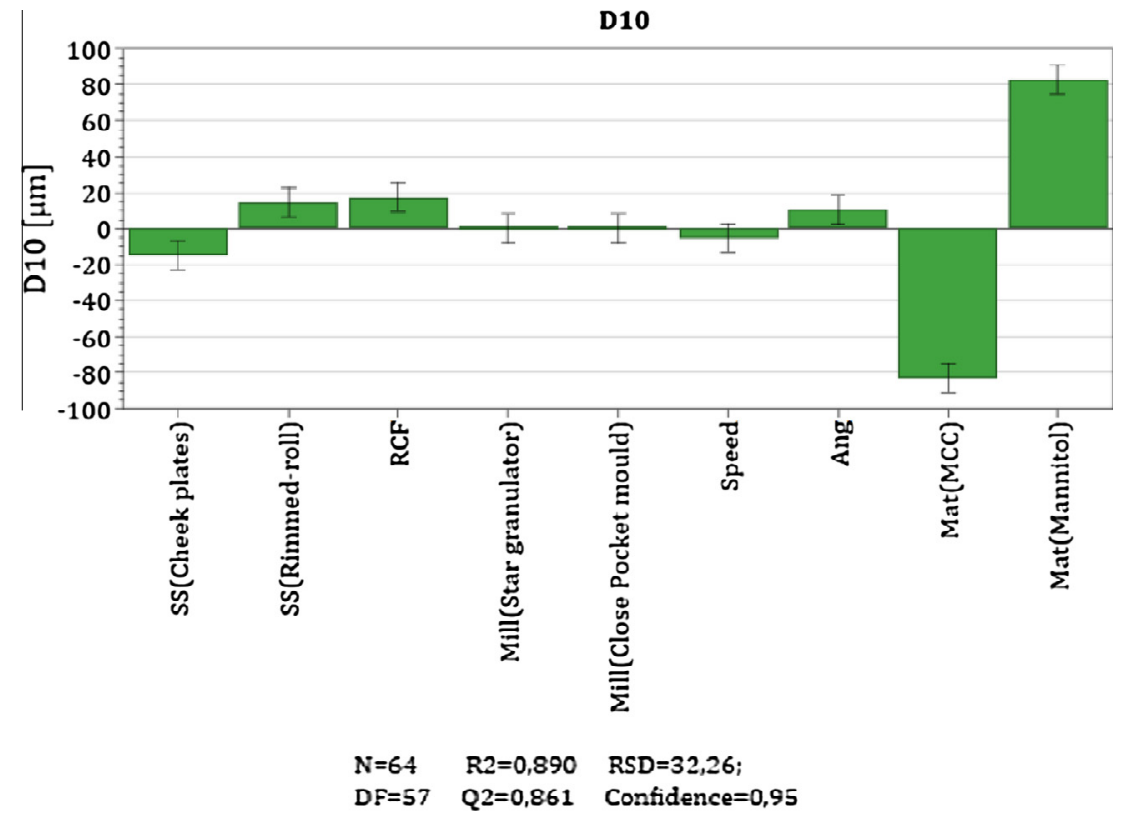

Fig. 11. Coefficient plot for $d_{10}(S S=$ sealing system, $R C F=$ Roll-compaction force; Ang = angle of rotation).

and using the rimmed-roll in order to reduce the amount of fines. The type of mill and the speed are considered non-significant factors (the confidence interval cross the X-axis), but the angle of oscillation has a direct influence; hence, the clockwise mode is preferred.

\subsection{Compactability}

In order to analyse the effect of roll compaction and milling conditions on the tablet properties, population class with particle sizes in the range $200-500 \mu \mathrm{m}$ was sampled by sieving in order 


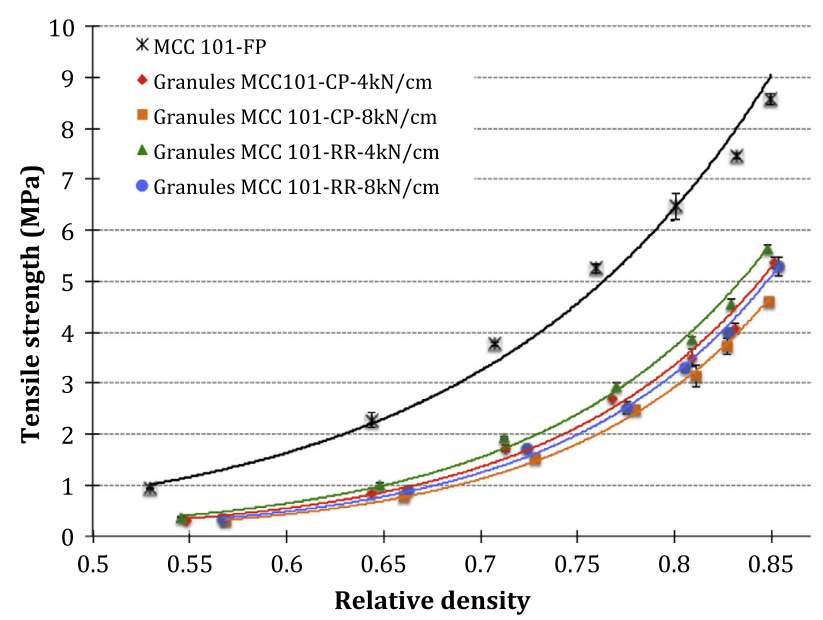

Fig. 12. Tensile strength as a function of relative density for $\mathrm{MCC}(\mathrm{CP}=\mathrm{Cheek}$ Plates, RR = Rimmed-roll; Roll compaction forces: 4 and $8 \mathrm{kN} / \mathrm{cm}$ ).

to reduce the impact of fine population on tablet properties. This procedure was applied to each batch.

3.5.1. How do roll-compaction conditions affect the compactability of tablets?

In Figs. 12 and 13, the tensile strengths are shown for feed powders and granules as a function of the tablet relative density.
Granules were produced after milling the different types of ribbons in the star granulator at $30 \mathrm{rpm}$ clockwise.

Regarding the excipients, as it was expected, the tablets produced with MCC had higher tensile strength. On the other hand, the compaction of mannitol takes place predominantly by brittle fracture and, therefore, the tensile strength is lower than for MCC.

Attending to the effect of roll-compaction process on the tensile strength of the tablets, it can be observed that lower tensile strength is achieved for granules than for original feed powders, mainly for MCC. This phenomenon of reduction in tensile strength after roll-compaction is known as "loss of reworkability" and it has been widely reported in the literature [8-14]. Plastic materials are more sensitive to this phenomenon than brittle materials, as it was reported by Wu and Sun [28]. The tablets made with mannitol show very low mechanical resistance and the variation of the values of the tensile strength depending on the conditions is less significant.

For both excipients, results showed that the lowest tensile strength was obtained when the powders were roll compacted with cheek plates. On the one hand, as it was seen in Section 3.4, working with rimmed-roll reduced the amount of fines. On the other hand, rimmed-roll system had less "loss of reworkability" than cheek plates. This is probably resulting from the mode of how stresses are applied on the ribbon. Indeed, in the cheek-plates case, the ribbon undertakes shearing stresses due to the friction between the powder and the seal wall whereas in rimmed-roll, the ribbon is more confined as in die compaction.

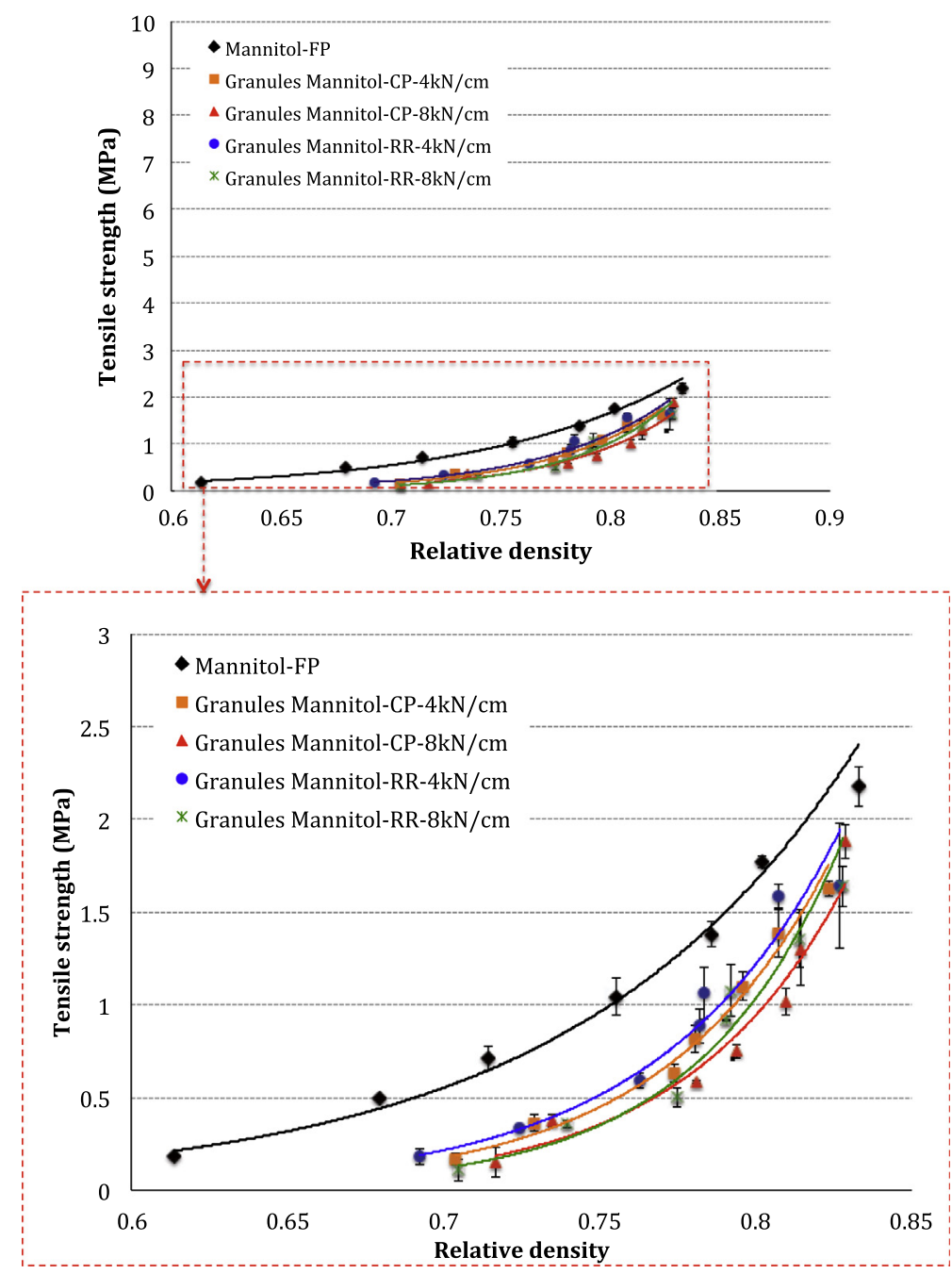

Fig. 13. Tensile strength as a function of relative density for mannitol $(\mathrm{CP}=$ Cheek Plates, $\mathrm{RR}=\mathrm{Rimmed}$-roll; Roll compaction forces: 4 and $8 \mathrm{kN} / \mathrm{cm})$. 


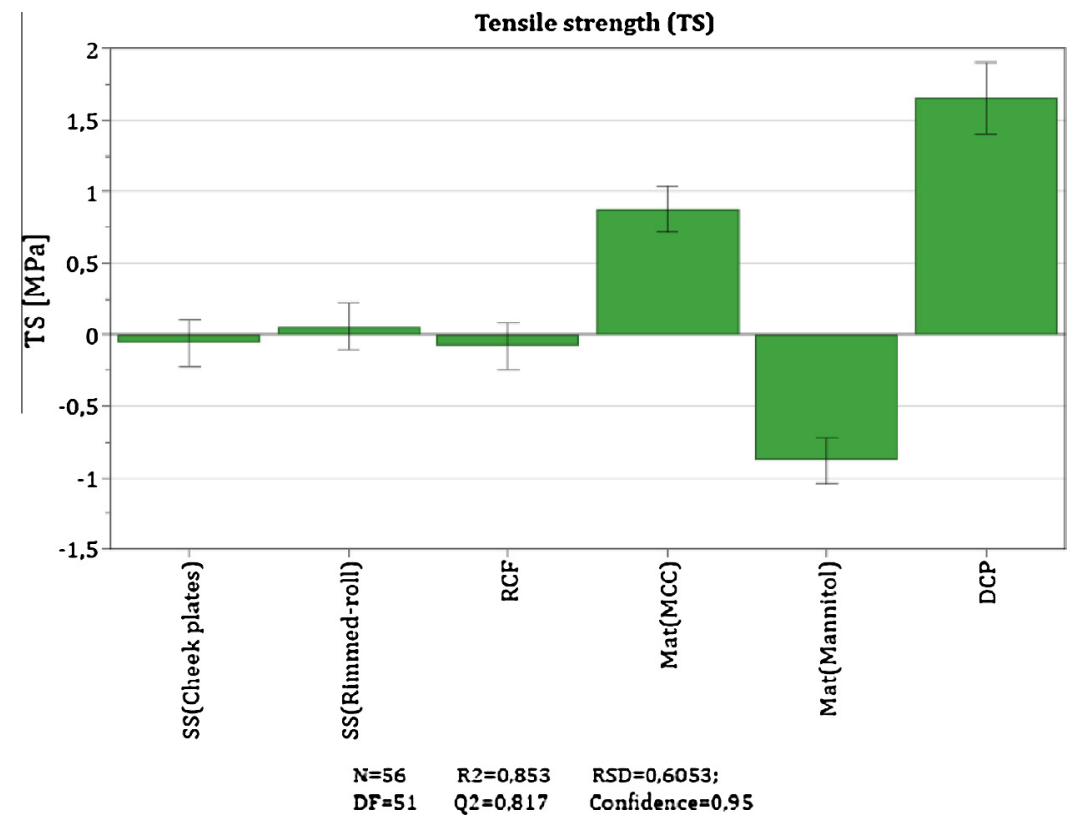

Fig. 14. Coefficient plot for tensile strength for different roll-compaction conditions $(S S=$ sealing system, RCF = Roll-compaction force; Ang = angle of rotation; DCP = diecompaction pressure).

Regarding the roll-force, the higher is the level of compaction, the harder are the granules and, hence, more significant is loss of reworkability. Nevertheless, the tensile strength of tablets produced under different roll-compaction conditions has similar values.

The coefficient plot (Fig. 14) shows a non-significant effect of the roll-compaction conditions on the tensile strength (specific compaction force and sealing system assembled). The reduction in tensile strength after roll-compaction is evident when granules are compared to feed powder, but slightly different values are obtained for granules obtained under different roll-compaction conditions. Obviously, the die-compaction pressure (DCP) and the material behaviour under compression are the most noteworthy factors.

3.5.2. How do milling-conditions affect the compactability of tablets?

As it was seen in Section 3.4, different milling conditions can lead to different particle size distributions. During die filling, particle size distribution has a direct effect on the segregation of particles inside the die and this can create afterwards a gradient of tablet density and a heterogeneity of the API content. It was reported in the literature that different milling systems and impellers can drive to different milling mechanisms [20]. But, is there any effect of the milling system on the mechanical properties of granules under compression? In this work, the compactability of granules was used to evaluate the effect of various milling parameters on the mechanical properties of granules. For this goal, granules obtained under different milling conditions were tableted. In this section, results show tablet tensile strength of granules in the range [200-500 $\mu \mathrm{m}$ ] obtained from ribbons of MCC and mannitol under $4 \mathrm{kN} / \mathrm{cm}$ of roll compaction force and cheek plates.

Tables 3 and 4 show the tensile strength of tablets for granules of MCC and mannitol obtained under different milling conditions (clockwise and oscillating) for two different die compaction pressures: 40 and $100 \mathrm{MPa}$.

As it was shown in Section 3.5.1, the tensile strength obtained for mannitol tablets is lower than for MCC. Regarding the milling parameters, results show that tensile strength of tablets produced at the same die compaction pressure has similar values, regardless of the mill type, speed and angle of rotation.
Table 3

Tensile strength of tablets for granules of MCC obtained under different milling conditions ( $\mathrm{CW}=$ Clockwise; OSC = Oscillating) for two different die compaction forces.

\begin{tabular}{clrll}
\hline \multicolumn{3}{l}{ Tensile strength (MPa) } & & \\
\hline Milling system & $\begin{array}{l}\text { Angle of } \\
\text { rotation }\end{array}$ & $\begin{array}{l}\text { Speed values } \\
(\mathrm{rpm})\end{array}$ & $\begin{array}{l}\text { Die compaction } \\
\text { pressure }\end{array}$ \\
\cline { 3 - 5 } & & $40 \mathrm{MPa}$ & $100 \mathrm{MPa}$ \\
\hline Star granulator & Clockwise & 30 & $1.33 \pm 0.02$ & $4.11 \pm 0.07$ \\
& $360^{\circ}$ & 120 & $1.41 \pm 0.04$ & $4.43 \pm 0.16$ \\
& Oscillating & 30 & $1.42 \pm 0.04$ & $4.55 \pm 0.10$ \\
& $150^{\circ}$ & 120 & $1.43 \pm 0.15$ & $4.51 \pm 0.04$ \\
Pocket mould- & Clockwise & 30 & $1.43 \pm 0.05$ & $4.57 \pm 0.11$ \\
grooved & $360^{\circ}$ & 120 & $1.34 \pm 0.05$ & $4.64 \pm 0.11$ \\
& Oscillating & 30 & $1.42 \pm 0.05$ & $4.49 \pm 0.14$ \\
& $150^{\circ}$ & 120 & $1.39 \pm 0.02$ & $4.45 \pm 0.20$ \\
\hline
\end{tabular}

Table 4

Tensile strength of tablets for granules of mannitol obtained under different milling conditions $(\mathrm{CW}=$ Clockwise; $\mathrm{OSC}=$ Oscillating $)$ for two different die compaction forces.

\begin{tabular}{clrll}
\hline \multicolumn{3}{l}{ Tensile strength (MPa) } & & \\
\hline Milling system & $\begin{array}{l}\text { Angle of } \\
\text { rotation }\end{array}$ & $\begin{array}{l}\text { Speed values } \\
(\mathrm{rpm})\end{array}$ & $\begin{array}{l}\text { Die compaction } \\
\text { pressure }\end{array}$ \\
\cline { 3 - 5 } & & $40 \mathrm{MPa}$ & $100 \mathrm{MPa}$ \\
\hline Star granulator & Clockwise & 30 & $0.36 \pm 0.04$ & $1.10 \pm 0.07$ \\
& $360^{\circ}$ & 120 & $0.45 \pm 0.02$ & $1.06 \pm 0.20$ \\
& Oscillating & 30 & $0.39 \pm 0.04$ & $1.21 \pm 0.12$ \\
Pocket mould- & $150^{\circ}$ & 120 & $0.40 \pm 0.01$ & $1.28 \pm 0.16$ \\
grooved & Clockwise & 30 & $0.32 \pm 0.03$ & $1.25 \pm 0.09$ \\
& $360^{\circ}$ & 120 & $0.31 \pm 0.02$ & $1.25 \pm 0.10$ \\
& Oscillating & 30 & $0.35 \pm 0.02$ & $1.31 \pm 0.16$ \\
& $150^{\circ}$ & 120 & $0.33 \pm 0.02$ & $1.27 \pm 0.07$ \\
\hline
\end{tabular}

The coefficient plot (Fig. 15) confirms this statement, showing a non-significant effect of the milling conditions on the tensile strength. It is in agreement with what was confirmed by Vendola and Hancock [21] that the mill type and the obtained granule size 


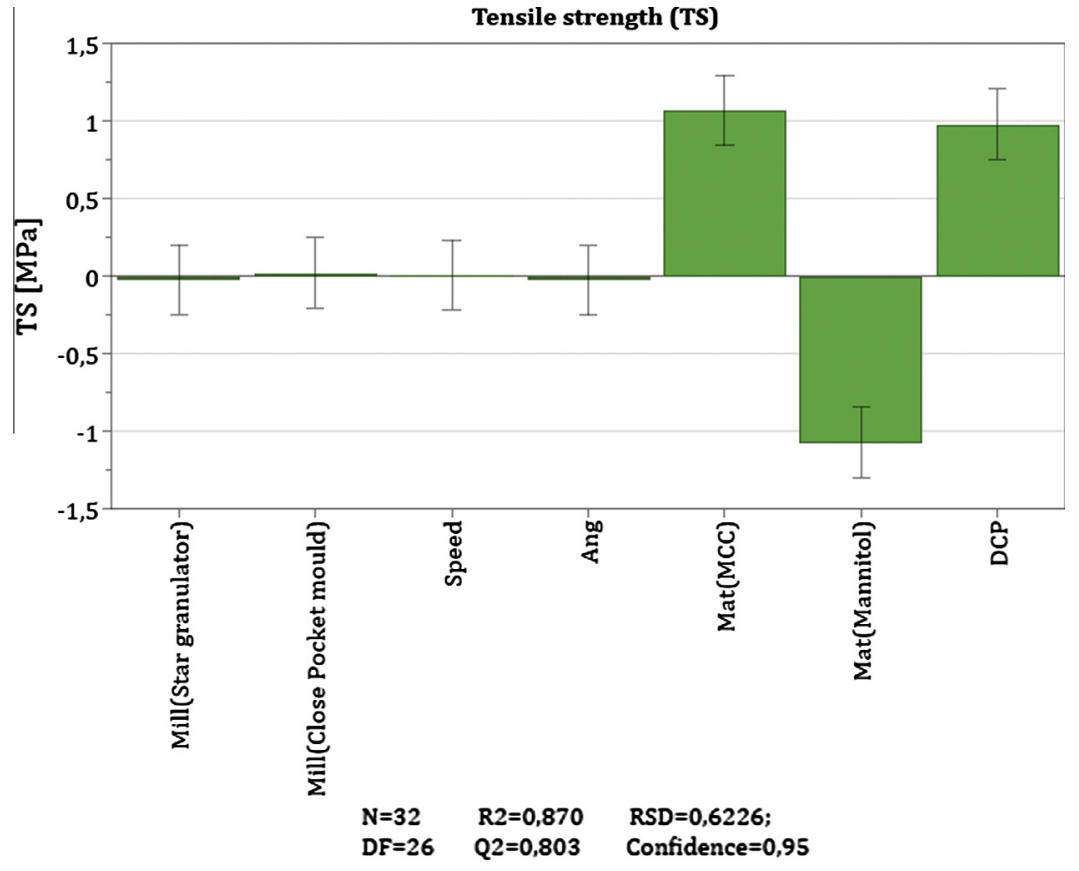

Fig. 15. Coefficient plot for tensile strength for different milling conditions (Ang = angle of rotation; DCP = die-compaction pressure).

distribution did not greatly influence the compactability. As it was shown before, obviously, the die-compaction pressure (DCP) and the material behaviour under compression are the most relevant factors. Thus, it can be concluded in this study, that there is no significant effect of milling conditions on the mechanical properties of granules under die compaction.

\section{Conclusions}

The objective of this work was to study the effects of roll-force, sealing system design and milling systems conditions on the produced granules of MCC and mannitol and their impact on the tablet properties. In this study, two roll-forces ( 4 and $8 \mathrm{kN} / \mathrm{cm}$ ) were applied and two different sealing conditions (cheek plates and rimmed-roll) were used to produce ribbons. After, the ribbons were milled using two milling systems (star and pocket mouldgrooved) with different operating conditions (milling speed: 30 and $120 \mathrm{rpm}$; rotation mode: clockwise- $360^{\circ}$ and oscillating$150^{\circ}$ ) to generate granules, they are used further in tableting process. The ultimate interest of the results is to determine and discuss the operating conditions that can improve the quality of granules and tablets.

To reach that goal, it is necessary to find a balance between a good flowability (reducing the amount of fines produced during the milling step) and the loss of reworkability during die compaction (caused by roll compaction).

The obtained results showed that it is preferable to work at high roll-compaction force and rimmed-roll as sealing system in order to reduce the amount of fines produced.

For MCC, the minimum percentage of fines (higher value of $d_{10}$ ) is produced when ribbons are produced at $8 \mathrm{kN} / \mathrm{cm}$ using rimmedroll and milled at $30 \mathrm{rpm}$ clockwise using star granulator as milling system. On the contrary, for mannitol, the higher value of $d_{10}$ is obtained for ribbons produced at $8 \mathrm{kN} / \mathrm{cm}$ with rimmed-roll system milled at $30 \mathrm{rpm}$ clockwise with the pocket mould-grooved granulator. Nevertheless, according to the minimal fines approach and the statistical analysis, the roll-compaction effect is predominant over the milling effect for the generation of fines, mainly for plastic materials.

On the other hand, the characterization of loss of compactability of granules under die compaction showed that with the rimmedroll system at low roll-compaction force slightly stronger tablets are produced. However, based on the statistical analysis, the rollcompaction and milling conditions are not significant factors on the tensile strength.

\section{Acknowledgement}

This project has received funding from the European Union's Seventh Framework Programme for research, technological development and demonstration under Grant agreement No. 316555. The authors would like to thank AstraZeneca (Macclesfield, UK) for giving access to Geopyc.

\section{References}

[1] P. Kleinebudde, Roll compaction/dry granulation: pharmaceutical applications, Eur. J. Pharm. Biopharm. 58 (2004) 317-326.

[2] M.G. Herting, P. Kleinebudde, Roll compaction/dry granulation: effect of raw material particle size on granule and tablet properties, Int. J. Pharm. 338 (2007) $110-118$.

[3] S. Inghelbrecht, J.P. Remon, The roller compaction of different types of lactose, Int. J. Pharm. 166 (1998) 135-144.

[4] P. Guigon, O. Simon, Roll press design - influence of force feed systems on compaction, Powder Technol. 130 (2003) 41-48.

[5] F. Freitag, K. Reincke, J. Runge, W. Grellmann, P. Kleinebudde, How do roll compaction/dry granulation affect the tableting behaviour of inorganic materials? Microhardness of ribbons and mercury porosimetry measurements of tablets, Eur. J. Pharm. Sci. 22 (2004) 325-333.

[6] C.M. Wagner, M. Pein, J. Breitkreutz, Roll compaction of mannitol: compactability study of crystalline and spray-dried grades, Int. J. Pharm. 453 (2) (2013) 416-422.

[7] C.M. Wagner, M. Pein, J. Breitkreutz, Roll compaction of granulated mannitol grades and the unprocessed crystalline delta-polymorph, Powder Technol. 270 (2014) 470-475.

[8] S. Malkowska, K.A. Khan, Effect of re-compression on the properties of tablets pre- pared by dry granulation, Drug Dev. Ind. Pharm. 9 (1983) 331-347.

[9] C. Sun, M.W. Himmelspach, Reduced tabletability of roller compacted granules as a result of granule size enlargement, J. Pharm. Sci. 95 (2006) 200-206. 
[10] S. Inghelbrecht, J.P. Remon, Roller compaction and tableting of microcrystalline cellulose/drug mixtures, Int. J. Pharm. 161 (2) (1998) 215224.

[11] M.G. Herting, P. Kleinebudde, Studies on the reduction of tensile strength of tablets after roll compaction/dry granulation, Eur. J. Pharm. Biopharm. 70 (2008) 372-379.

[12] C. Bacher, P.M. Olsen, P. Bertelsen, J.M. Sonnergaard, Compressibility and compactibility of granules produced by wet and dry granulation, Int. J. Pharm. 358 (2008) 69-74.

[13] M. Šantl, I. Ilić, F. Vrečer, S. Baumgartner, A compressibility and compactibility study of real tableting mixtures: the impact of wet and dry granulation versus a direct tableting mixture, Int. J. Pharm. 414 (2011) 131-139.

[14] F. Freitag, P. Kleinebudde, How do roll compaction/dry granulation affect the tableting behaviour of inorganic materials? Comparison of four magnesium carbonates, Eur. J. Pharm. Sci. 19 (2003) 281-289.

[15] T. Kuntz, M.a. Schubert, P. Kleinebudde, Increased compactibility of acetames after roll compaction, Eur. J. Pharm. Biopharm. 77 (1) (2011) 164-169.

[16] R. Miller, Roller compaction technology, in: D.M. Parikh (Ed.), Handbook of Pharmaceutical Granulation Technology, Marcel Dekker, New York, 1997.

[17] A.M. Miguélez-Morán, C.Y. Wu, H. Dong, J.P.K. Seville, Characterisation of density distributions in roller-compacted ribbons using micro-indentation and X-ray micro-computed tomography, Eur. J. Pharm. Biopharm. 72 (2009) 173182.

[18] Y. Funakoshi, T. Asogawa, E. Satake, Use of a novel roller compactor with a concave-convex roller pair to obtain uniform compacting pressure, Drug Dev. Ind. Pharm. 3 (1977) 555-573.
[19] E.L. Parrott, Densification of powders by concavo-convex roller compactor, J. Pharm. Sci. 70 (1981) 288-291.

[20] A.K. Samanta, K.Y. Ng, P.W.S. Heng, Cone milling of compacted flakes: process parameter selection by adopting the minimal fines approach, Int. J. Pharm. 422 2012) 17-23.

[21] T.A. Vendola, B.C. Hancock, The effect of mill type on two dry-granulated placebo formulations, Pharm. Technol. 32 (2008) 72-86.

[22] A. Pérez Gago, P. Kleinebudde, MCC-mannitol mixtures after roll compaction/ dry granulation: percolation thresholds for ribbon microhardness and granule size distribution, Pharm. Dev. Technol. 7450 (2016) 1-11.

[23] J.T. Fell, J.M. Newton, Determination of tablet strength by the diametralcompression test, J. Pharm. Sci 59 (1970) 688-691.

[24] P.G. Karehill, M. Glazer, C. Nystrom, Studies on direct compression of tablets. XXIII. The importance of surface roughness for the compactability of some directly compressible materials with different bonding and volume reduction properties, Int. J. Pharm. 64 (1990) 35-43.

[25] B. Mitra, J. Hilden, J.D. Litster, Novel use of monodisperse granules to deconvolute impacts of granule size versus granule solid fraction on tablet tensile strength, Adv. Powder Technol. 26 (2) (2015) 553-562.

[26] S. Abdel-Hamid, F. Alshihabi, G. Betz, Investigating the effect of particle size and shape on high speed tableting through radial die-wall pressure monitoring, Int. J. Pharm. 413 (2011) 29-35.

[27] S. Inghelbrecht, J.P. Remon, Reducing dust and improving granule and tablet quality in the roller compaction process, Int. J. Pharm. 171 (1998) 195-206.

[28] S.-J. Wu, C. Sun, Insensitivity of compaction properties of brittle granules to size enlargement by roller compaction, J. Pharm. Sci. 96 (5) (2007) 1445-1450. 